\title{
Knowledge, Attitude and Practice of Women Towards Female Genital Mutilation in Lejet Kebele, Dembecha Woreda, Amhara Regional State, Northwest, Ethiopia, 2014
}

\author{
Nurilign Abebe Moges ${ }^{1,}$, Getachew Mullu ${ }^{1}$, Mihiretie Gedfew ${ }^{1}$, Mohammednur Redi ${ }^{1}$, \\ Mohammed Molla ${ }^{1}$, Setarg Ayenew ${ }^{1}$, Shegaw Fentahun ${ }^{1}$, Solomon Adisie ${ }^{1}$, Zewudu Dagnew ${ }^{2}$ \\ ${ }^{1}$ Nursing department, medicine and health Sciences College, Debre Markos University, Debre Markos, Ethiopia \\ ${ }^{2}$ Public health department, medicine and health sciences college, Debre Markos University, Debre Markos, Ethiopia
}

Email address:

nure113@gmail.com (N. A. Moges)

To cite this article:

Nurilign Abebe Moges, Getachew Mullu, Mihiretie Gedfew, Mohammednur Redi, Mohammed Molla, Setarg Ayenew, Shegaw Fentahun, Solomon Adisie, Zewudu Dagnew. Knowledge, Attitude and Practice of Women Towards Female Genital Mutilation in Lejet Kebele, Dembecha Woreda, Amhara Regional State, Northwest, Ethiopia, 2014. Journal of Gynecology and Obstetrics.

Vol. 3, No. 2, 2015, pp. 21-25. doi: 10.11648/j.jgo.20150302.11

\begin{abstract}
Introduction: Female genital mutilation (FGM) is cutting away part of the female external genitalia or other injuries to the female genitalia for cultural purpose. This practice is against human reproductive health rights with many serious consequences in physical, mental, social and psychological makeup of girls. Therefore, study the prevalence of FGM among under five daughters, knowledge about the ill health effects of FGM and attitude of mothers towards FGM was timely to recommend the concerned body according to the findings. Methods and materials: community based cross sectional study design was among 235 women with under five years of age daughters. Systematic random sampling was used and data were entered in to Epi data version 3.1 then exported to SPSS version 16 for further analysis. Bivariate and multivariate logistic regression was fitted to identify associated factors. Result: about $94 \%$ of mothers and $34 \%$ of their under five daughters were circumcised. More than half of them had positive attitude to continue FGM practice with poor knowledge about ill health effects of FGM. Conclusion and recommendation: Majority of women were in poor knowledge of the ill health effects of FGM. Most of them had favorable attitude to continue FGM among their daughters. The practice of FGM is very high among women and under five daughters. Most of the FGM practices were done in the seventh days of life. The government should strength the legal measurement taken on FGM practice involvers. The woreda health office should strengthened HTP/FGM discouragement through health extension workers (HEW), community leaders and women involvement. Continued community conversation on the ill health effects of FGM should be implemented.
\end{abstract}

Keywords: FGM, Circumcise, Children

\section{Introduction}

Female genital mutilation (FGM) is cutting away part of the female external genitalia or other injuries to the female genitalia for cultural purpose (WHO, 1995). Though, the reason for practicing FGM varies from society to society. The major cultural reason can be to maintain moral behavior of women, to further virginity, for hygienic reason, to calm the girl make her descent, for religious requirement, to avoid difficulty at delivery and to increase matrimonial opportunities (NCTPE, 1999).

A global review of FGM shows that the custom of FGM is known to be practiced in one form or on other in more than 28 countries in Africa including Ethiopia (4). According to a survey carried out in 1987 by national committee on traditional practice of Ethiopia (NCTPE), more than $80 \%$ of women in the country (100\% in certain communities) are circumcised. It also says $60 \%$ of Ethiopian women support the practice. In places where FGM takes place it is performed during infancy, childhood or at adolescence (NCTPE, 1999).

But there is less attention for FGM practice in Amhara regional state probably by assuming the practice is decreased yet still there is high prevalence in rural communities of Ethiopia. This was evidenced from 2005 Ethiopian Demographic and Health Survey (EDHS) the prevalence was 
$74 \%$ in the region and not studied in 2011 EDHS (EDHS, 2005 and 2006). This practice is against human reproductive health rights with many serious consequences in physical, mental, social and psychological makeup of girls. Therefore, study the prevalence of FGM among under five daughters, knowledge about the ill health effects of FGM and attitude of mothers towards FGM was timely to recommend the concerned body according to the findings.

\section{Objectives}

\subsection{General Objective}

To assess knowledge, attitude and practice of women towards FGM and associated factors in Lejet kebele Dembecha woreda, Northwest Ethiopia, 2014

\subsection{Specific Objectives}

To determine level of knowledge of women related to ill health effects of FGM

To determine level of attitude of women towards FGM practice

To determine the prevalence of FGM practice among under five daughters

To identify factors associated with FGM practice

\section{Methods and Materials}

Study design: Community based cross-sectional study was conducted.

Study area and period: Lejet kebele Dembecha woreda, West Gojjam zone, Amhara regional state of Ethiopia. On the main road AA to Bahrdar $7 \mathrm{~km}$ away from Dembecha, $43 \mathrm{~km}$ from D/markos and $212 \mathrm{~km}$ from Bahrdar According to Lejet kebele health post report of 2013, Lejet kebele had a total population of 6003 of which 811 were females at reproductive age groups and 863 were under five children. The study was conducted from April 27-May 4, 2014

Source population: All women who had daughter less than 5 years

Sample size determination: using single population proportion formula

$\mathrm{P}=74 \%$ in 2005 EDHS, 95\% CI, 5\% marginal error and using correction formula. Thus $\mathrm{n}=235$ women paired with under five female children

Sampling technique: Systematic random sampling method was used $(811 / 235=4)$. Then if the $4^{\text {th }}$ household did not have under five daughters the next house were considered. If there were more than one under five children the smallest in age was asked for practice and if more than one women in a house lottery method was used to select respondents

\subsection{Operational Definition}

Knowledge: Good if answer more than half of 10 knowledge questions and poor knowledge if they answer less than the specified questions.

Attitude: Favorable against FGM: if score greater than the mean value from 12 attitude measuring questions and unfavorable if score less than the mean value

Practice: Being circumcised as evidenced from women's response

Data collection and analysis: Interview adminstered questioner by $4^{\text {th }}$ year clinical nursing students was carried out. Data were entered into epi data version 3.1 and further exported to SPSS version 16 for analysis using binary and multivariate logistic regression. Significance was assessed at $95 \%$ CI with p-values less than 0.05 .

\subsection{Ethical Consideration}

A formal letter was written from Debre Markos University was submitted to Dembecha health office and permission was obtained. Verbal consent was obtained from women after the objective of the study is mentioned. All matters of confidentiality were assured.

\section{Result}

A total of 234 mothers were included in the present study with hundred percent response rates. Respondents' average age was $29.35+$ SD 7.75 years. Almost all of them (99.1\%) were orthodox in religion and all of them were from Amhara in ethnicity. Some $198(84.6 \%)$ were married. More than two-thirds of their occupations were farmers (Table 1).

Table 1. Socio-demographic Characteristics of the women in Lejet kebele, Dembecha woreda, northwest Ethiopia, April to May, $2014 n=234$.

\begin{tabular}{lll}
\hline & Frequency & Percentage \\
\hline Age & 71 & \\
$15-24$ & 101 & 30.3 \\
$25-34$ & 62 & 43.2 \\
$>35$ & & 26.5 \\
Marital status & 198 & \\
Married & 28 & 84.6 \\
Divorced & 8 & 12 \\
Others & & 3.4 \\
Educational status & 108 & \\
Cannot read and write & 50 & 46.2 \\
Can read and write only & 55 & 21.4 \\
Primary school completed & 21 & 23.5 \\
High school and above & & 9 \\
Occupational status & 203 & \\
Farmer & 22 & 203 \\
Merchant & 9 & 9.4 \\
Others & & 3.8 \\
\hline
\end{tabular}

\subsection{Knowledge of Mothers towards the Effect of FGM}

All of the respondents ever heard about female genital mutilation. Source of information were from radio/TV 40 (17.1\%), from public meeting $22(9.4 \%)$, from health facilities $73(31.2 \%)$, from school 57 (24.4\%) and 42 (17.9\%) other sources. Some 128 (54.7\%) were aware that FGM can cause bleeding as health effect. Over all knowledgeable were $108(46.2 \%)$ and $126(53.8 \%)$ were poor in knowledge (Table 2). 
Table 2. Knowledge of women about the ill health effects of FGM in Lejet kebele, Dembecha woreda, Amhara Regional state, northwest Ethiopia, 2014.

\begin{tabular}{lll}
\hline Knowledge questions & Yes (percentage) & No(percentage) \\
\hline the health effects of FGM on bleeding & $125(54.7)$ & $106(45.3)$ \\
the health effects of FGM for infection & $105(44.9)$ & $129(55.1)$ \\
the health effects of FGM complication during labor & $98(41.9)$ & $136(58.1)$ \\
the health effects of FGM other if any & $2(0.9)$ & $232(99.1)$ \\
FGM has health problem & $55(23.5)$ & $179(76.5)$ \\
There is law against FGM & $66(28.2)$ & $168(71.8)$ \\
Does FGM is harmful & $163(69.7)$ & $71(30.3)$ \\
Does FGM result in tearing at child birth? & $98(41.9)$ & $136(58.1)$ \\
FGM facility HIV transmission & $151(64.5)$ & $83(35.35)$ \\
Does FGM result in scare formation? & $93(39.7)$ & $141(60.3)$ \\
Knowledgeable & $108(46.2 \%)$ & $126(53.8 \%)$ \\
\hline
\end{tabular}

\subsection{Attitude Towards FGM}

Over attitudes of mothers towards FGM were assessed using mean value as cut of point to classify as favorable and unfavorable attitude towards against FGM practices. Then the mean values is 38.4 based on this mother with favorable attitude to continue FGM were $112(47.9 \%)$ and with unfavorable attitude $122(52.1 \%)$ that is to discontinue the practice. Attitude scores from strongly agree to strongly disagree given a value ranges from 1 to 5 then add up to give a minimum of 12 and a maximum of 60 (Table 3 )

Table 3. Attitude of women about the practice of FGM in Lejet kebele, Dembecha woreda, Amhara Regional state, northwest Ethiopia, 2014.

\begin{tabular}{|c|c|c|c|c|c|}
\hline Attitude question & Strongly agree $(\%)$ & Agree (\%) & Neutral (\%) & Disagree (\%) & Strongly disagree $(\%)$ \\
\hline FGM prevents premarital sex? & $4(1.7)$ & $27(11.5)$ & $118(50.4)$ & $78(33.3)$ & $7(3)$ \\
\hline FGM is a good practice & $15(6.4)$ & $44(18.8)$ & $24(10.3)$ & $113(48.3)$ & $38(16.2)$ \\
\hline FGM decrease promiscuity? & $5(2.1)$ & $12(5.1)$ & $149(63.7)$ & $55(23.5)$ & $13(5.6)$ \\
\hline FGM decrease sexual pleasure? & $4(1.7)$ & $28(12)$ & $137(58.5)$ & $59(25.2)$ & $6(2.6)$ \\
\hline FGM cause sexual dysfunction? & $11(4.7)$ & $51(21.8)$ & $80(34.2)$ & $80(34.2)$ & $12(5.1)$ \\
\hline FGM makes genitalia more attractive & $5(2.1)$ & $10(4.3)$ & $108(46.2)$ & $87(37.2)$ & $24(10.3)$ \\
\hline Will you encourage FGM? & $15(6.4)$ & $50(21.4)$ & $11(4.7)$ & $119(50.9)$ & $39(16.7)$ \\
\hline Do you think that FGM make child birth easier? & $16(6.8)$ & $59(25.2)$ & $41(17.5)$ & $81(34.5)$ & $37(15.8)$ \\
\hline FGM protect virginity? & $6(2.6)$ & $42(17.9)$ & $58(24.8)$ & $97(41.5)$ & $31(13.2)$ \\
\hline Do you support that the practice of FGM & $13(5.6)$ & $57(24.4)$ & $13(5.6)$ & $109(46.6)$ & $42(17.9)$ \\
\hline $\begin{array}{l}\text { Women should actively participate in reductions of } \\
\text { FGM. }\end{array}$ & $52(22.2)$ & 105 (44.9) & $14(6)$ & $52(22.2)$ & $11(4.7)$ \\
\hline
\end{tabular}

\subsection{Practice of FGM among Women and Under Five Children}

Female genital mutilation (FGM) was performed on 220 (94\%) of women and $80(34.2 \%)$ of under five children were circumcised. Still $60(25.6 \%)$ of women has intention to continue FGM (Table 4)

The practice was performed by untrained groups of people at different categories. Traditional birth attendants 80 (34.6\%), traditional healers $22(9.4 \%)$, and mother or father $33(14.1 \%)$ were reported as FGM practitioners. Regarding materials used for cutting new blade 106 (45.3\%), knife 21
(9\%), scissors $9(3.8 \%)$ and others $136(58.1 \%)$ were used as cutting materials.

Table 4. Practice of FGM in Lejet kebele, Dembecha woreda, Amhara Regional state, northwest Ethiopia, 2014.

\begin{tabular}{lll}
\hline Practice questions & Yes (\%) & No (\%) \\
\hline Is FGM performed on you? & $220(94 \%)$ & $14(6)$ \\
Do you routinely perform FGM? & $107(45.7)$ & $127(54.3)$ \\
Have you ever performed FGM in the past? & $150(64.1)$ & $84(35.9)$ \\
Is your daughter circumcised? U5 & $80(34.2)$ & $154(65.8)$ \\
Will you perform in the future & $60(25.6)$ & $174(74.4)$ \\
\hline
\end{tabular}

Table 5. Bivariate and multivariate logistic regression of FGM practice and associated factors of women for their under five children in Lejet Kebele, Dembecha Woreda, Amhara Regional state northwest Ethiopia, 2014.

\begin{tabular}{lllll}
\hline \multirow{2}{*}{ Characteristics } & FGM & & COR at 95\% CI & AOR at 95\% CI \\
\cline { 2 - 3 } & Yes & No & & \\
\hline Age & 24 & 47 & 1 & \\
$17-24$ & 26 & 75 & $0.67(0.35-1.32)$ & $1.84(0.91-3.70)$ \\
$25-34$ & 30 & 32 & & 1 \\
$>35$ & & & & $1.18(0.42-3.31)$ \\
Marital status & 66 & 132 & $16(0.67-3.35)$ & 0.75 \\
Married & 12 & & & 1.5 \\
Divorced & & & \\
\hline
\end{tabular}




\begin{tabular}{|c|c|c|c|c|c|}
\hline \multirow{2}{*}{ Characteristics } & \multicolumn{2}{|c|}{ FGM } & \multirow{2}{*}{ COR at $95 \%$ CI } & \multirow{2}{*}{ AOR at $95 \%$ CI } & \multirow{2}{*}{ P-value } \\
\hline & Yes & No & & & \\
\hline Others & 2 & 6 & $0.67(0.13-3.39)$ & $0.80(0.12-5.37)$ & 0.81 \\
\hline \multicolumn{6}{|l|}{ Educational status } \\
\hline Cannot read and write & 56 & 52 & $7.2(3.31-15.27)$ & $1.71(0.60-4.90)$ & 0.32 \\
\hline Can read and write only & 14 & 36 & $2.57(1.02-6.36)$ & $0.99(0.32-3.06)$ & 0.99 \\
\hline Primary school and above & 10 & 66 & 1 & 1 & \\
\hline \multicolumn{6}{|l|}{ Occupational status } \\
\hline Farmer & 75 & 128 & $3.05(1.12-8.27)$ & $2.56(0.77-8.56)$ & 0.13 \\
\hline Merchant & 5 & 26 & 1 & & \\
\hline \multicolumn{6}{|l|}{ Knowledge } \\
\hline poor & 65 & 61 & $6.61(3.46-12.63)$ & $3.36(1.39-8.13)$ & 0.007 \\
\hline good & 15 & 93 & 1 & 1 & \\
\hline \multicolumn{6}{|l|}{ Attitude } \\
\hline Unfavorable against FGM & 69 & 53 & $11.95(5.8-24.50)$ & $8.88(4.15-18.96)$ & 0.000 \\
\hline Favorable against FGM & 11 & 101 & 1 & & \\
\hline
\end{tabular}

\section{Discussion}

This study tried to assess the prevalence of under five daughters FGM, knowledge of mothers towards the harmful effect of FGM and attitudes towards their under five daughters circumcision among mothers in Lejet Kebele, Dembecha Woreda, northwest Ethiopia.

Knowledge of mothers towards the harmful effects of FGM were $108(46.2 \%)$ of women had good knowledge about the ill health effect of FGM and 126 (53.8\%) of the mothers had poor knowledge about the ill health effect of FGM. This is lower than a study in Addis Ababa which was $92 \%$ of women had good knowledge (Spadacini B etal, 1998). This discrepancy is because of socio-demographic difference among the two study populations in which the later study was conducted in the capital city more women were expected to be knowledgeable than this rural mothers about the ill health effects of FGM. On the other hand $66.9 \%$ women in Somali (Bayoudh Fet al, 1995) had good knowledge on the effects of FGM. This might be because of massive governmental and nongovernmental intervention in Somalia against the practice. Therefore, FGM knowledge is very poor in this study area that needs intervention from health professionals, government and other concerned bodies.

Attitude of mothers against FGM practice was only 112 (47.9\%) had positive/favorable attitude against FGM practice meaning less than half of them believe to discourage FGM practice. And 122 (52.1\%) had unfavorable attitude against FGM this implies that majority of them would like to continue FGM among their daughters. Meanwhile $25.6 \%$ of them support to continue FGM for various reasons. BUT 90\% of women did not support FGM practice in Gambella region of Ethiopia which is the region with very good practice in FGM aspect (Bayoudh Fet al, 1995). Similarly 60\% of women support FGM in Ethiopia (NCTP/EC, 1999) but this study is still higher than other African countries like 30\% in Kenya and $36 \%$ in Nigeria women were supporting the continuation of the FGM practice. Hence an attitude of women towards continuation of FGM practice is high that needs combination of efforts from different stalk holders.

Practice of FGM among women and under five children in this study area were $94 \%$ of mother had undergone FGM and
$34.2 \%$ of under five daughters had undergo FGM by traditional healers, Traditional birth attendant (TBA), family members using different equipments like new blade, knife and scissors. In this study FGM was commonly practiced at $7^{\text {th }}$ day of life $(63 \%)$ followed by $9^{\text {th }}$ day $(15 \%)$ and $8^{\text {th }}$ day (9.4\%). The time for FGM practice is similar with Yemen practiced at age less than two weeks (Nirobi, 2005). Similarly, $65 \%$ of Ethiopian women were circumcised in the nation (NCTP/EC, 1999) the difference can be the second study is nationwide which included cities and rural while the current study concentrate only in rural kebele. This study is consistent with FGM practice in other African countries such as $28 \%$ in Senegal, $42 \%-60 \%$ in Egypt and $92 \%$ in Mal (Nirobi, 2005)

In the multivariate logistic analysis, only Knowledge and attitude were significant associated factors with FGM practice. Those with poor knowledge were 3.36 times more likely to practice FGM on their daughter than with good knowledge 3.36, (1.39-8.13). Those with unfavorable attitude against FGM were 8.88 times more likely to practice FGM on their daughter than with favorable attitude i.e 8.88 (4.1518.96). This is true since knowledge and attitude are the prerequisite to practice. Mothers with good knowledge of harm full effects of the FGM more likely not to support the practice and in turn not engage/or participate the practice. This implies educate mothers about the harmful effects of FGM will help them to develop positive attitude to stop the practice.

\section{Conclusion}

- Majority of women were in poor knowledge of the ill health effects of FGM

- Most of them had favorable attitude to continue FGM among their daughters

- The practice of FGM is very high among women and under five daughters

- Most of the FGM practice were done in the seventh days of life

- Poor knowledge and favorable attitude towards FGM practice were significant factors for FGM practice in the study area 


\section{Recommendations}

- $\quad$ The government should strength the legal measurement taken on FGM practice involvers

- The woreda health office should strengthened HTP/FGM discouragement through HEW, community leaders and women involvement

- Continued community conversation on the ill health effects of FGM should be implemented

- Health professionals should give due attention during ANC and other maternal health services since most of them under go FGM at $7^{\text {th }}$ day of life

- Further qualitative research is recommended to dig out possible reasons to support FGM

\section{Acknowledgements}

We would like to pass our gratitude thank to Debre markos university for the ethical clearance, to Dembecha Woreda health office, kebele administrators and study participants for their genuine information and participation.

\section{References}

[1] Analysis of current abandonment approach, Nirobi, 2005 (accessed Feb. 8, 2012)
[2] Bayoudh F, Barrak S, Ben Fredj N, Allani R, Hamdi M. Study of a custom in Somalia: the circumcision of girls. Med Trop (Mars) 1995; 55(3):238-42.

[3] Central statistical authority (CSA) and Ethiopian demographic and health survey study, 2005.

[4] Central statistical authority (CSA) and Ethiopian demographic and health survey study, 2011.

[5] NCTPE/EC, FGM, national committee on traditional practices of Ethiopia, Addis Ababa Ethiopia, Dec.1999

[6] NCTPE/EC. Major harmful traditional practice in Ethiopia: resource material for higher training institutes, NCTPE Addis Ababa Ethiopia, Dec 1999

[7] Spadacini B, Nichols P. Campaigning against female genital mutilation in Ethiopia using popular education.Gend Dev1998;6(2):44-52.

[8] WHO progress in sexual and reproductive health research Geneva WHO: 2006

[9] World Health Organization. Female genital mutilation, Report of a WHO Technical Working Group, Geneva: WHO 1995. 